\title{
Assessment of the Effects of Perineoplasty on Female Sexual Function
}

\author{
Cihan İnan ${ }^{1}$, Meriç Çağrı Ağır², Fulya Gökdağlı Sağır³, Atınç Özer ${ }^{4}$, Özlem Özbek ${ }^{5}$, Hakan Dayanır \\ Gökçe Sayg1 Uysal ${ }^{6}$, Onur Uysal ${ }^{6}$
}

\footnotetext{
${ }^{1}$ Department of Obstetrics and Gynecology, Kulu State Hospital, Konya, Turkey ${ }^{2}$ Department of Obstetrics and Gynecology, Ereğli State Hospital, Konya, Turkey ${ }^{3}$ Department of Obstetrics and Gynecology, Sason State Hospital, Batman, Turkey ${ }^{4}$ Department of Obstetrics and Gynecology, Arnavutköy State Hospital, İstanbul, Turkey ${ }^{5}$ Department of Anesthesiology and Reanimation, Kulu State Hospital, Konya, Turkey ${ }^{6}$ Department of Otorhinolaryngology, Kulu State Hospital, Konya, Turkey
}

Background: The scar tissue formed by episiotomy during vaginal delivery, and the related pain, is very frequent. The change in the normal anatomy can cause cosmetic and physiologic problems. It can affect and cause deterioration in sexual functions. Therefore, making the right diagnosis and applying the right surgical procedures are very important.

Aims: Our aim was to examine the effect of the perineoplasty operation on the sexual dysfunctions that present due to vaginal delivery.

Study Design: Self-controlled study.

Methods: Forty patients, who attended our clinic between April 2012 and May 2013, and who were between the ages of 20 and 50 years, were included in the study. The patients had complaints of scar tissue in the perineum and various sexual dysfunctions after vaginal delivery, and they were suitable for perineoplasty. The Female Sexual Function Index (FSFI) questionnaire was applied to the patients before and 6 months after the operation, and the results were compared.

Results: After the perineoplasty operation, there was a statistically significant improvement in the patients in the domains of sexual desire, arousal, lubrication, orgasm, and sexual satisfaction $(\mathrm{p}<0.005)$. However, there was no significant improvement in the feeling of pain during sexual intercourse $(p=0.184)$. The mean \pm SD total FSFI score increased significantly after the operation $(\mathrm{p}<0.005)$.

Conclusion: The sexual dysfunctions that develop due to perineal damage during vaginal delivery can benefit significantly from the perineoplasty operation if the indications are correct. However, vaginal perineoplasty did not provide an improvement in dyspareunia.

Keywords: Female, perineoplasty, sexual dysfunction
Sexual dysfunctions are very frequent ailments in society, which include pain during sexual intercourse, decrease in sexual desire, sexual arousal disorders, and orgasm problems (1). Female sexual dysfunction is often multi-factorial, and can derive from psychological and physiological causes.

Traumas of the perineum that affect the neurologic and vascular functions of tissues are an important cause of female sexual dysfunctions. In particular, the lacerations that form after vaginal delivery and the episiotomies during labor have a negative effect on sexual functions. Genital area traumas can cause a weakening of the pelvic floor muscles and disrupt their integrity. In the long-term, this can cause urinary and anal incontinence, as well as sexual dysfunction (2).

Various surgical procedures have been developed to correct the negative effects of the genital area traumas. The genital aesthetic surgical procedures include hymenoplasty, labiaplas- 
ty and vaginoplasty (3). Perineoplasty is a surgical procedure that corrects the cicatricial area in the perineal region, and includes the restoration of perineal muscles $(4,5)$. In addition to being a surgical procedure used to correct the perineal deformities after delivery, perineoplasty is also used as a surgical procedure for genital warts, vulvar vestibulitis, vaginismus, decreased sexual sensation, congenital deformities, and intraoital stenosis (5).

There are a limited number of studies in the literature that analyze the effects of the perineoplasty operation on female sexual function. In some of those studies, perineoplasty was performed along with different gynecological operations. In some studies, the operation was performed to treat complaints due to an organic pathology, such as granuloma fissuratum and lichen sclerosus. There are very few studies that focus on the effects of perineoplasty performed solely to correct the perineal defects presenting after vaginal delivery on female sexual function. In our study, we aimed to examine the effects of the perineoplasty operation on sexual dysfunctions deriving from perineal defects, such as scar tissue in the perineum, tears, and intraoital looseness that present after vaginal delivery.

\section{MATERIALS AND METHODS}

This prospective, self-controlled study included 40 patients between 20 and 50 years of age, who attended our clinic between April 2012 and May 2013 and had a perineoplasty operation. The approval of the ethics committee was taken from the Ethics Committee of Selçuk University Faculty of Medicine. Informed consents were provided. The study group consisted of patients who had complaints such as aesthetic concerns of the cicatricial tissue in the perineum due to episiotomy during vaginal delivery, abnormal sensations during sexual intercourse, loosening of the vaginal opening, lack of pleasure in sexual intercourse, pain during sexual intercourse, and swelling of the vaginal opening. None had a history of previous vaginal or urogynecologic operations. The vaginal examinations of the patients revealed that they had perineal tears, the introitus was loose, and there were cicatricial tissues in the episiotomy incision line.

The patients had a mediolateral or median episiotomy in the perineum fourchette region, and scar tissue with a length of minimum $2 \mathrm{~cm}$ and maximum $4 \mathrm{~cm}$ due to vaginal delivery. The patient with the earliest vaginal delivery gave birth 8 months previously. The following patients were not included in the study: patients with congenital or acquired labial hypertrophy, introital stenosis, or looseness not due to vaginal delivery; patients with lesions due to the oncologic diseases of the perineum, or chronic or acute inflammatory diseases; and patients with dominant psychiatric problems. In addition, patients below the age of 20 and above 50, and patients who had urogynecological operations that might affect sexual function, were not included in the study.

Demographic information of the patients including their medical backgrounds and delivery histories were recorded. Patients receiving drugs that can affect sexual function, such as antidepressant, anticholinergic, antihistaminic, barbiturate, estrogen, or antiandrogenic drugs, were excluded from the study. Patients who did not have an active sex-life were excluded.

Initially, there were 83 patients complaining of various sexual dysfunctions that presented after vaginal delivery. The real cause was considered to be psychiatric problems for some patients $(n=4)$, and there was no perineal defect in some patients $(n=11)$. Perineoplasty operation was performed on 68 patients. There were 28 patients who were excluded due to the reasons explained above. Finally, 40 patients were included in the study (Figure 1).

The Female Sexual Function Index (FSFI) is an index designed to assess aspects of female sexual function. The structure of this index covers six domains: desire, arousal, lubrication, orgasm, satisfaction, and pain. The frequency and level of sexual desire or interest were assessed in the $1^{\text {st }}$ and $2^{\text {nd }}$ questions (score range: 1-5); the frequency and level of arousal, and the confidence about and satisfaction with arousal were assessed in the 3-6 ${ }^{\text {th }}$ questions (score range: $0-5$ ); the frequency and difficulty of lubrication (wetness), and the maintenance and difficulty of maintaining lubrication during sexual intercourse were assessed in the $7-10^{\text {th }}$ questions (score range: $0-5$ ); the frequency and difficulty of reaching orgasm, and the satisfaction with it were assessed in the $11-13^{\text {th }}$ questions (score range: $0-5$ ); the satisfaction with the amount of emotional closeness with their partner, the level of satisfaction in the current sexual relationship, and in overall sex-life were assessed in the 14$16^{\text {th }}$ questions (score range: $0-1$ and 5) (score range: $0-5$ ); the frequency of discomfort or pain during and following vaginal penetration and its level were assessed in the $17-19^{\text {th }}$ questions (score range: $0-5$ ). Simple mathematical algorithm calculations were made to identify the scores of the domains and the whole scale. After the domain averages were multiplied with factor loads, the highest score that could be received from the scale was 36.0 and the lowest was 2.0. We used the validated FSFItotal cut-off score of 26.55 to classify women with and without FSD (6). There is a Turkish language version of this form, and it has been validated for the Turkish society (7).

In our study, the FSFI questionnaire was applied to the patients before the operation. Perineoplasty is a surgical procedure in which the cicatricial and loose tissue in the vulvar vestibule, vaginal introitus, and distal vagina is excised, su- 


\begin{tabular}{|c|c|}
\hline $\begin{array}{l}\text { Patients } \\
\text { complaining } \\
\text { from various } \\
\text { sexual } \\
\text { dysfunctions that } \\
\text { presented after } \\
\text { vaginal delivery } \\
(\mathrm{n}=83)\end{array}$ & \multirow{2}{*}{$\begin{array}{l}\text { Perineoplasty operation } \\
\text { was not performed on some } \\
\text { patients }(\mathrm{n}=15) \\
\text { - } \quad \text { Patients with psychiatric } \\
\text { problems }(\mathrm{n}=4) \\
\text { - } \quad \text { Patients who did not have } \\
\text { any defect such as tear, } \\
\text { scar or intraoital looseness } \\
\text { in }(\mathrm{n}=11)\end{array}$} \\
\hline & \\
\hline $\begin{array}{l}\text { Number of } \\
\text { patients who had } \\
\text { perineoplasty } \\
\text { operation }(n=68)\end{array}$ & \multirow{3}{*}{$\begin{array}{l}\text { Patients excluded from the } \\
\text { study }(\mathrm{n}=21) \\
\text { - } \quad \text { Patients who said they } \\
\text { did not understand the } \\
\text { questions }(\mathrm{n}=6) \\
\text { - } \quad \text { Patients above the age of } \\
50(\mathrm{n}=2) \\
\text { - } \quad \text { Patients who did not want } \\
\text { to participate in the study } \\
(\mathrm{n}=6) \\
\text { - Patients who previously } \\
\text { had uro-gynecologic } \\
\text { operations ( } \mathrm{n}=3) \\
\text { Patients using drugs } \\
\text { such as anticholinergic, } \\
\text { antihistaminic, estrogen } \\
\text { drugs }(\mathrm{n}=4)\end{array}$} \\
\hline$\nabla$ & \\
\hline $\begin{array}{l}\text { Number of } \\
\text { patients to whom } \\
\text { Female Sexual } \\
\text { Function Index } \\
\text { (FSFI) questions } \\
\text { were asked } \\
(n=47)\end{array}$ & \\
\hline$\nabla$ & \multirow{2}{*}{$\begin{array}{l}\text { Patients excluded from the } \\
\text { study }(\mathrm{n}=7) \\
\text { - } \quad \text { Patients who did not have } \\
\text { active sexual lives after } \\
\text { the operation }(\mathrm{n}=5) \\
\text { - } \quad \text { Patients who gave } \\
\text { conflicting responses } \\
\text { so considered to be not } \\
\text { giving accurate answers } \\
(\mathrm{n}=2)\end{array}$} \\
\hline $\begin{array}{l}\text { Patients included } \\
\text { in the study } \\
(\mathrm{n}=40)\end{array}$ & \\
\hline
\end{tabular}

FIG. 1. Flow of participants through the study

perficial transverse and levator muscles are brought closer to the perineal middle line, and the perineum and pelvic floor are raised (8). We can summarize the operations we performed as follows. First, the introitus sub-region was held with allis clamps, including the fourchette. One allis clamp was held from the rear vaginal mucosa. The vaginal mucosa was freed with a few sharp dissections. After that, the cicatricial mucocutaneous region from the introitus to the upper anus part was excised. The dimensions of the excised tissue were adjusted according to the size of the cicatricial tissue in the perineum. Bilateral levator sutures were placed and tied. Continuous su- tures were placed in the vaginal mucosa. The superficial perineal muscles (bulbocavernosus and superficial lateral perineal muscles) were brought together, and the skin was sutured one by one skin was sutured by simple interrupted stitch. None of the patients had additional procedures, such as genital plastic operations (labioplasty, vaginoplasty, or hymenoplasty) or functional operations (cystocele or rectocele). The questionnaire was re-applied to the patients 6 months after the surgery. Thus, the differences between the preoperative and postoperative periods were compared.

\section{Statistical analysis}

The analyses were made with the Statistical Package for Social Sciences version 20 (SPSS, IBM Corp., CA, USA). Paired sample $t$-tests were used to score the preoperative and postoperative changes in the FSFI collectively and separately for each domain. Correlation analyses were made to determine differences in the collective and separate scoring of the domains before and after the operation. The Chi-square test was used to identify whether there was a significant percentile difference between the groups. All tests were performed in a twoway manner, and the statistical significance was set at $\mathrm{p}<0.05$.

\section{RESULTS}

The average age of the patients included in our study was $32.88 \pm 7.12$ years. All patients had a history of vaginal delivery, and the average number of vaginal deliveries was $2.43 \pm 1.13$ (Table 1). Forty per cent of the patients $(n=16)$ had two vaginal deliveries, and $25 \%(\mathrm{n}=10)$ had three vaginal deliveries. Most of our patients were in the age group of 20-35 years $(\mathrm{n}=29)$, and had low- or middle-income levels. Their education levels indicated that $87.5 \%$ of the patients $(n=35)$ were primary school graduates.

The reasons for the patients' attendance at our clinic revealed that the most common cause of complaint was a lack of pleasure in sexual intercourse ( $87.5 \%$ of the patients; $n=35$ ). This complaint was followed by aesthetic concerns, especially due to scars in the episiotomy incision line and tears in the perineum $(62.5 \%$; $\mathrm{n}=25)$, and by the feeling of swelling of the vaginal opening $(62.5 \% ; n=25)$. These were followed by dyspareunia, which is the feeling of pain during sexual intercourse $(20 \% ; n=8)$.

According to the FSFI test applied to the patients before the operation, the cut-off value of the total score was 26.55 , and $72.5 \%$ of the patients $(\mathrm{n}=29)$ had an explicit sexual dysfunction. After the operation, the number of patients who had an explicit sexual dysfunction declined to $32.5 \%(\mathrm{n}=13 ; \mathrm{p}=0.001$; Table 2). 
According to the FSFI questionnaire applied to the patients before and after the perineoplasty operation, there was a statistically significant improvement in the domains of sexual desire, sexual arousal, lubrication during intercourse, having orgasm, and sexual satisfaction after the operation $(p<0.05)$. There was no statistically significant improvement in the domain of pain during

TABLE 1. Characteristics of women who had perineoplasty operation

\begin{tabular}{lll}
\hline & Mean \pm SD & Minimum-maximum \\
\hline Age & $32.88 \pm 7.12$ & $20-48$ \\
Income level (TL) & $1073.75 \pm 785.04$ & $0-4000$ \\
Marriage duration (years) & $12.45 \pm 7.37$ & $2-33$ \\
Gravidity & $3.28 \pm 1.58$ & $1-7$ \\
Parity & $2.6 \pm 1.06$ & $1-5$ \\
Previous vaginal deliveries & $2.43 \pm 1.13$ & $1-5$ \\
Previous cesarean section & $0.18 \pm 0.38$ & $0-1$ \\
\hline
\end{tabular}

SD: standard deviation; TL: Turkish lira sexual intercourse $(\mathrm{p}=0.184)$. When the total score in FSFI was assessed, the mean preoperative total score was $23.9 \pm 4.6$, and the mean postoperative total score was $27.1 \pm 4.6(\mathrm{p}<0.05$; Table 3$)$.

\section{DISCUSSION}

According to our study, the preoperative and postoperative differences indicate that the perineoplasty operation is successful in improving sexual function and the quality of life

TABLE 2. Comparison of patients' preoperative and postoperative sexual dysfunction

\begin{tabular}{lllll}
\hline & \multicolumn{2}{c}{ Preoperative } & \multicolumn{2}{c}{ Postoperative } \\
Sexual function & Number & $\%$ & Number & $\%$ \\
\hline Dysfunction & 29 & 72.5 & 13 & 32.5 \\
Normal & 11 & 27.5 & 27 & 67.5 \\
\hline
\end{tabular}

(Chi-square value: $12.832, \mathrm{p}=0.001$ )

TABLE 3. Female Sexual Function Index values in women who had a perineoplasty operation

\begin{tabular}{|c|c|c|c|c|c|}
\hline \multirow[b]{2}{*}{ Main criteria and titles } & \multicolumn{2}{|c|}{ Preoperative } & \multicolumn{2}{|c|}{ Postoperative } & \multirow[b]{2}{*}{$\mathrm{p}$ value } \\
\hline & Mean \pm SD & $\begin{array}{c}\text { Minimum- } \\
\text { maximum }\end{array}$ & Mean \pm SD & $\begin{array}{c}\text { Minimum- } \\
\text { maximum }\end{array}$ & \\
\hline Desire & $3.29 \pm 0.79$ & $1.2-4.8$ & $3.76 \pm 0.98$ & $1.2-5.4$ & $<0.001$ \\
\hline 1. Desire: frequency & $1.67 \pm 0.48$ & $0.6-3$ & $1.92 \pm 0.61$ & $0.6-3$ & $<0.001$ \\
\hline 2. Desire: level & $1.62 \pm 0.39$ & $0.6-2.4$ & $1.87 \pm 0.46$ & $0.6-2.4$ & 0.001 \\
\hline Arousal & $3.54 \pm 1.22$ & $1.2-5.4$ & $4.11 \pm 1.28$ & $1.2-5.7$ & $<0.001$ \\
\hline 3. Arousal: frequency & $0.88 \pm 0.39$ & $0.3-1.5$ & $1.01 \pm 0.39$ & $0.3-1.5$ & 0.001 \\
\hline 4. Arousal: level & $0.79 \pm 0.28$ & $0.3-1.2$ & $0.92 \pm 0.29$ & $0.3-1.5$ & $<0.001$ \\
\hline 5. Arousal: confidence & $0.92 \pm 0.37$ & $0.3-1.5$ & $1.07 \pm 0.39$ & $0.3-1.5$ & 0.001 \\
\hline 6. Arousal: satisfaction & $0.96 \pm 0.42$ & $0.3-1.8$ & $1.13 \pm 0.38$ & $0.3-1.8$ & $<0.001$ \\
\hline Lubrication & $4.5 \pm 1.27$ & $1.2-6$ & $5.04 \pm 1.13$ & $1.2-6$ & $<0.001$ \\
\hline 7. Lubrication: frequency & $1.16 \pm 0.33$ & $0.3-1.5$ & $1.25 \pm 0.3$ & $0.3-1.5$ & 0.009 \\
\hline 8. Lubrication: difficulty & $1.17 \pm 0.35$ & $0.3-1.5$ & $1.3 \pm 0.34$ & $0.3-1.5$ & $<0.001$ \\
\hline 9. Lubrication: frequency of maintaining it & $1.09 \pm 0.43$ & $0.3-1.5$ & $1.23 \pm 0.36$ & $0.3-1.5$ & $<0.001$ \\
\hline 10. Lubrication: difficulty & $1.09 \pm 0.39$ & $0.3-1.5$ & $1.27 \pm 0.34$ & $0.3-1.5$ & $<0.001$ \\
\hline Orgasm & $3.73 \pm 1.05$ & $1.2-6$ & $4.58 \pm 1.2$ & $1.2-6$ & $<0.001$ \\
\hline 11. Orgasm: frequency & $1.11 \pm 0.41$ & $0.4-2$ & $1.42 \pm 0.44$ & $0.4-2$ & $<0.001$ \\
\hline 12. Orgasm: difficulty & $1.18 \pm 0.39$ & $0.4-2$ & $1.53 \pm 0.48$ & $0.4-2$ & $<0.001$ \\
\hline 13. Orgasm: satisfaction & $1.48 \pm 0.39$ & $0.4-2$ & $1.65 \pm 0.39$ & $0.4-2$ & 0.001 \\
\hline Satisfaction & $4.67 \pm 1.51$ & $1.2-8$ & $5.09 \pm 1.32$ & $1.2-8$ & 0.001 \\
\hline 14. Satisfaction: value of emotional closeness with partner & $1.51 \pm 0.57$ & $0.4-2$ & $1.68 \pm 0.5$ & $0.4-2$ & 0.008 \\
\hline 15. Satisfaction: sexual relationship & $1.59 \pm 0.48$ & $0.4-2$ & $1.74 \pm 0.41$ & $0.4-2$ & 0.001 \\
\hline 16. Satisfaction: overall sex-life & $1.49 \pm 0.52$ & $0.4-2$ & $1.65 \pm 0.46$ & $0.4-2$ & 0.002 \\
\hline Pain & $4.15 \pm 1.56$ & $1.2-6$ & $4.49 \pm 1.47$ & $1.2-6$ & 0.184 \\
\hline 17. Pain: frequency during vaginal penetration & $1.3 \pm 0.61$ & $0.4-2$ & $1.4 \pm 0.59$ & $0.4-2$ & 0.38 \\
\hline 18. Pain: frequency following vaginal penetration & $1.5 \pm 0.84$ & $0.4-4$ & $1.54 \pm 0.58$ & $0.4-2$ & 0.694 \\
\hline 19. Pain: level during and following vaginal penetration & $1.41 \pm 0.44$ & $0.4-2$ & $1.54 \pm 0.43$ & $0.4-2$ & 0.156 \\
\hline Whole scale & $23.9 \pm 4.6$ & $11.6-32.7$ & $27.1 \pm 4.6$ & $10.6-33.3$ & $<0.001$ \\
\hline
\end{tabular}


for the patients who had defects, such as tearing or scaring in the perineal region, due to vaginal delivery. The patients had the operation in order to reduce their complaints and to improve their quality of life. The American College of Obstetricians and Gynecologists (ACOG) recommended that clinicians should discuss with patients their expectations before the operation, and inform them about the efficacy of these operations and their potential complications (9). In our study, we gave the necessary information to the patients about the potential complications, such as blood loss, infection risk, and postoperative pain.

There are several studies in the literature that examine the effects of perineal operations on sexual function. In the study by Goodman et al. (8), labioplasty, perineoplasty, and vaginoplasty operations were performed on 258 patients in a separate or combined manner. The researchers found a statistically significant improvement in the sexual function of the patients and their partners after the operation. Kahn et al. (10) studied the effects of posterior colporrhaphy on bowel and sexual function, and found that sexual dysfunction increased after the operation. Rouzier et al. (11) assessed the results of the perineoplasty operation performed on patients who had introital stenosis due to lichen sclerosus. They found that dyspareunia improved in $90 \%$ of the patients, and the quality of sexual life improved in $86 \%$. The study by Kennedy et al. (12) included patients who had granuloma fissuratum in the posterior fourchette. Dyspareunia complaints decreased in $64 \%$ of the sexually active patients who underwent an operation. Woodward et al. (13) analyzed the outcomes of perineoplasty in patients who had obstetric perineal laceration and persistent perineal pain. There was no scar or granulation tissue in the patients after the operation, and there was a statistically significant decrease in perineal pain, as well as a significant improvement in coitus frequency and satisfaction.

In the studies by Rouzier et al. (11) and Kennedy et al. (12), the reason for the significant decrease in dyspareunia after operation might be that the operation corrected the painful sclerotic lesions and sclerotic tightness due to organic pathologies, such as granuloma fissuratum and lichen sclerosus. In contrast to those studies, our study did not find any significant difference in dyspareunia, although our patients did not have any organic pathology. Furthermore, our patients had loosening due to vaginal delivery rather than tightening in the introitus. In the study by Woodward et al. (13), revision perineoplasty was performed on nine patients who had complaints of dyspareunia before surgery. In our study, only $20 \%$ patients complained of dyspareunia. This low rate might have contributed to the fact that there was no significant difference in the statistical analysis including all patients. In the study by Kahn et al. (10), the causes of sexual dysfunction and dyspareunia were attributed to the fact that half of the patients were postmenopausal, the vaginal and perineal tissues were atrophic, and some of those patients had a vaginal operation previously. In our study, the patients were selected from an age range in which the patients were sexually active and did not have atrophic tissue due to menopause. In addition, the patients had not undergone any previous vaginal or urogynecological operations. However, there was no improvement in the score for pain, and in our opinion, this is especially due to the newly formed ring formation in the fourchette after the operation, a degree of vaginal tightening, and the manifestation of vaginitis, which frequently presents in patients after operation.

In our study, the results indicate that the perineoplasty operation renders a significant improvement in female sexual function. Similarly, the studies by Goodman et al. (8), Rouzier et al. (11), and Woodward et al. (13) found a significant improvement in sexual function. In the vaginal examination we performed 6 months after the operation, we did not see any scar or granulation tissues in the perineum of patients. Woodward et al. (13) found no scar or granulation tissue after surgery in parallel with our results. We observed a significant increase in the FSFI scores after the operation. In the statistical analysis covering all patients, we observed a significant improvement in the domains of sexual desire, sexual arousal, lubrication, orgasm, and sexual satisfaction after the operation. Although there was no significant difference regarding dyspareunia, the total score was affected by the significant difference in the other five parameters in the FSFI, and a significant increase was detected in the total score after the operation. It is possible that the body image is disrupted in the patients that present perineal defect after vaginal delivery. The repair of the perineal defect might have increased the patients' confidence in their own bodies, which might have had a positive effect on the sexual function. Moreover, the decrease in the feeling of being rejected by their partners and in performance anxiety might have contributed to the improvements in patients' sexual function. The levator ani muscle plays an important role, especially in regulating the motor response of the vagina and orgasm. The rhythmic contractions in the vagina are very important during orgasm. In cases of hypotony of the muscles, vaginal sensation and orgasm intensity may decrease (14). In our perineoplasty operations, approximating the superficial perineal muscles to the middle line and placing levator sutures might have affected the motor functions of the perineal region positively, and in particular, may have contributed to making the rhythmic contractions during orgasm more regular.

In this study, we wanted to examine whether sexual dysfunction derived from perineal defects due to vaginal delivery improves after perineoplasty, and the results indicated a statistically significant improvement. This study has several limi- 
tations. There is an apparent need for studies on the subject with a larger numbers of patients. Only $20 \%$ of the patients had dyspareunia before the operation. If most of the patients had had this complaint or if it had been possible to work on a larger scale, it would have been possible to better observe the effects of the operation on dyspareunia. Being unable to follow the patients after surgery for a longer period of time is also another limiting factor for our study. In normal scar recovery phases, the maturation phase takes approximately up to 1 year, and perhaps if we had been able to follow the patients for 1 year after the operation, we would have better observed the effects of perineoplasty, especially on dyspareunia.

Perhaps the biggest challenge experienced in this study was the serious communication difficulties we had with the patients who were generally from the low and middle socioeconomic levels. The majority $(87.5 \%)$ of the patients were primary school graduates. It was very difficult to explain the FSFI questions and to get answers from the patients because of the reasons that were likely due to their social and cultural characteristics. We excluded the patients who said that they could not fully understand and did not want to answer the questions from our study. As a result, it is possible that the answers given could be affected by the social and cultural lives of the patients. Therefore, we think that it is necessary to conduct similar studies with patients coming from diverse sociocultural environments.

In conclusion, this study indicates that the perineoplasty operation leads to an improvement in women who have sexual dysfunction due to vaginal delivery. However, pain during sexual intercourse did not improve in this period. Further studies should examine the sustainability of the improvements over time, and whether the physiological, medical, and psychosocial factors play an intermediary role.

Ethics Committee Approval: Ethics committee approval was received for this study from the Ethics Committee of Selçuk University Faculty of Medicine (Approval Number: 2013/186).

Informed Consent: Written informed consent was obtained from patients who participated in this study.

Peer-review: Externally peer-reviewed.

Author contributions: Consept - C.İ., M.Ç.A., G.S.U.; Design - C.İ., F.G.S.; Supervision - Ö.Ö., H.D., O.U; Materials - G.S.U., M.Ç.A., H.D.; Data Collection \&/or Processing - F.G.S., A.Ö., Ö.Ö.; Analysis \&/or Interpretation - C.İ., O.U., A.Ö.; Literature Search C.İ., F.G.S.; Writting - C.İ., M.Ç.A., A.Ö.; Critical Reviews - H.D., O.U., Ö.Ö.
Conflict of Interest: No conflict of interest was declared by the authors.

Financial Disclosure: The authors declared that this study has received no financial support.

\section{REFERENCES}

1. Rosen R, Brown C, Heiman J, Leiblum S, Meston C, Shabsigh $\mathrm{R}$, et al. The female sexual function index (FSFI): a multidimensional self-report instrument for the assessment of female sexual function. J Sex Marital Ther 2000;26:191-208. [CrossRef]

2. Glazener CM. Sexual function after childbirth: women's experiences, persistent morbidity and lack of professional recognition. Brit J Obstet Gynaecol 1997;104:330-5. [CrossRef]

3. Dobbeleir JM, Landuyt KV, Monstrey SJ. Aesthetic surgery of the female genitalia. Semin Plast Surg 2011;25:130-41. [CrossRef]

4. Goodman MP. Female cosmetic genital surgery. Obstet Gynecol 2009;113:154-9. [CrossRef]

5. Woodruff JD, Genadry R, Poliakoff S. Treatment of dyspareunia and vaginal outlet distortions by perineoplasty. Obstet Gynecol 1981;57:750-4.

6. Wiegel M, Meston C, Rosen R. The female sexual function index (FSFI): cross-validation and development of clinical cut-off scores. J Sex Marital Ther 2005;31:1-20. [CrossRef]

7. Oksuz E, Malhan S. Reliability and validity of the female sexual function index in Turkish population. Sendrom 2005;17:54-60.

8. Goodman MP, Placik OJ, Benson RH, Miklos JR, Moore RD, Jason RA, et al. A large multicenter outcome study of female genital plastic surgery. J Sex Med 2010;7:1565-77. [CrossRef]

9. Committee on Gynecologic Practice, American College of Obstetricians and Gynecologists. ACOG Committee Opinion No. 378: Vaginal "rejuvenation" and cosmetic vaginal procedures. Obstet Gynecol 2007;110:737-8. [CrossRef]

10. Kahn MA, Stanton SL. Posterior colporrhaphy: its effects on bowel and sexual function. Br J Obstet Gynaecol 1997;104:826. [CrossRef]

11. Rouzier R, Haddad B, Deyrolle C, Pelisse M, Moyal-Barracco M, Paniel BJ. Perineoplasty for the treatment of introital stenosis related to vulvar lichen sclerosus. Am J Obstet Gynecol 2002;186:49-52. [CrossRef]

12. Kennedy CM, Dewdney S, Galask RP. Vulvar granuloma fissuratum: a description of fissuring of the posterior fourchette and the repair. Obstet Gynecol 2005;105:1018-23. [CrossRef]

13. Woodward AP, Matthews CA. Outcomes of revision perineoplasty for persistent postpartum dyspareunia. Female Pelvic Med Reconstr Surg 2010;16:135-9. [CrossRef]

14. Berman JR. Physiology of female sexual function and dysfunction. Int J Impot Res 2005;17:44-51. [CrossRef] 